\title{
Affordances and the Contents of Perception
}

\section{Citation}

Siegel, Susanna. 2014. Affordances and the Contents of Perception. In Does Perception Have Content?, ed. Berit Brogaard. Oxford: Oxford University Press

\section{Published Version}

https://global.oup.com/academic/product/does-perception-have-content-9780199756018?

$\mathrm{cc}=\mathrm{us} \&$ lang=en\&\#

\section{Permanent link}

http://nrs.harvard.edu/urn-3:HUL.InstRepos:33907957

\section{Terms of Use}

This article was downloaded from Harvard University's DASH repository, and is made available under the terms and conditions applicable to Open Access Policy Articles, as set forth at http:// nrs.harvard.edu/urn-3:HUL.InstRepos:dash.current.terms-of-use\#OAP

\section{Share Your Story}

The Harvard community has made this article openly available.

Please share how this access benefits you. Submit a story.

Accessibility 


\title{
Affordances and the Contents of Perception* \\ Susanna Siegel \\ Forthcoming in Does Perception Have Content? \\ Ed. B. Brogaard. Oxford University Press. 2014.
}

\begin{abstract}
A hole in the ground protects some creatures but endangers others. Dry ground is passable by creatures who walk, but fatal for a fish. These environments provide different possibilities for different creatures.

J. J. Gibson invented the word "affordance" to denote possibilities of action for a creature that are given by the environment. ${ }^{1}$ He proposed that we perceive affordances, and that the paradigmatic perceptions are byproducts of action plans. These proposals inspired an "action-first" approach to visual perception, which foregrounds the role of the perceiver as an actor.
\end{abstract}

The action-first approach to visual perception can be contrasted with the "spectator-first" approach, which foregrounds the role of the perceiver as an observer. This approach is heir to David Marr's computational theory of vision, and like Marr's theory, it gives a central role in perception to belief-like representations. Here the paradigmatic perceptions are observations of scenes with which one does not necessarily interact, such as watching a sunset.

In recent years, both of these approaches have been used to investigate the nature of perceptual experience, leading to a divide over the centrality of representation in analyzing perception. ${ }^{2}$ On the surface, the two approaches are easily reconciled by the hypothesis that affordances are on par with color and shape as properties represented in experience. ${ }^{3}$ But even if affordances could in principle be represented in experience, it is reasonable to ask whether they have to be so represented - or whether instead we simply experience affordances without representing them. If any representations of affordances would be an idle wheel in

\footnotetext{
* For extensive discussion and criticism, thanks to audiences at Harvard, Rice, Geneva, Charleston, Madison, Oslo, Glasgow, Copenhagen, Princeton, and Universidad

Autónoma de México, as well as to John Bengson, Ned Block, Berit Brogaard, Alex Byrne, Jeremy Dolan, Anya Farennikova, Grace Helton, Sheridan Hough, Zoe Jenkin, Sean Kelly, Fiona Macpherson, Eric Mandelbaum, Farid Masrour, Laura Perez, Álvaro Peláez, Sebastian Rödl, and Charles Siewert, and to Miguel-Angel Sebastian and Anna Bergqvist for writing comments on several drafts. Thanks most of all to Sebastian Watzl for many illuminating conversations about every aspect of this material.

${ }^{1}$ Gibson (1977)

${ }^{2}$ Proponents of the action-first approach include Hurley (1998), Noe (2006), Kelly (2006, 2010), Orlandi (forthcoming). Proponents of spectator-first approach include Byrne (2009), Chalmers (2005), Pautz (2010), Peacocke (1995), Siegel (2010).

${ }^{3}$ For developments of this idea, see Bengson (ms) and Nanay (2011).
} 
explaining the function and character of perceptual experience, that would go some way toward vindicating the action-first approach. And if most properties presented in experience could be shown to involve affordances, that would suggest that representation in general is an idle wheel in perception. ${ }^{4}$

In this paper, I draw out a challenge to the centrality of representation in perceptual experience that arises from an important class of experiences of affordances. These are experiences of the environment as compelling you to act in a way that is solicited or afforded by the environment. I call such experiences experienced mandates. They are generally structured by how you are already acting in a situation - not only by how you can act or are disposed to act in it. From your point of view, the environment pulls actions out of you directly, like a force moving a situation, with your actions in it, from one moment to the next. Experiences like these were discussed by Merleau-Ponty in the 1960's, and they figure prominently in recent discussions by Hubert Dreyfus, Adrian Cussins, and Sean Kelly, among others. ${ }^{5}$ These experiences help us make sense of the idea that affordances could be experienced without being represented: the environment invites or solicits an activity, and you experience these affordances by doing, or feeling moved to do, what they invite you to do. From these experiences we can reconstruct a challenge to the primacy of representation in perception.

We can use experienced mandates to ask three questions about the role of representation in perception.

\section{Q1. Do experienced mandates have any representational contents?}

Q2. Do experienced mandates have any representational contents relevant to explaining why it makes sense to the subject to perform the action she experiences as mandated?

Q3. Is there any proposition that could reflect the mandate that the subject experiences, if that proposition were the content of the experience?

I'm going to assume that experienced mandates have perceptual experiences as a part, and that an experienced mandate counts as having representational contents if its component perceptual experience does. Questions Q1-Q3 then bear directly on the role of representation in perceptual experience. Regarding Q1, if experienced mandates have no representational content, then their component perceptual experiences do not either, challenging the primacy of representation in perceptual experience. Regarding Q2, if experienced mandates have no contents relevant to explaining the associated

\footnotetext{
${ }^{4}$ Kelly (2006) suggests that experiences of color and shape are always experienced mandates, in which colors and shapes solicit us to view them in certain ways, and that none of these experiences involve representation.

${ }^{5}$ Merleau-Ponty, The Phenomenology of Perception, Kelly (2005), Cussins (1990), Dreyfus $(2002,2005)$.
} 
actions, then no component perceptual experiences do either, challenging the explanatory relevance of any representational contents perceptual experiences may have. Regarding Q3, if we could identify a proposition that would characterize the mandate that the subject experiences, then representational contents could in principle help to illuminate this distinctive phenomenon.

To assess these questions, I explain more fully what experienced mandates are and how they challenge the primacy of representation in experience in Part I, and then I address all three questions in Part II, where I argue that the answer to all of them is Yes.

Once these questions are on the table, it is natural to wonder whether mandates are represented in certain perceptual experiences - not just whether any representational contents could in principle reflect the feeling of an action being solicited and mandated by an object or situation. Since the stronger thesis that mandates are represented in experienced mandates entails positive answers to questions Q1-Q3, one could reach the conclusions I defend here in one fell swoop by defending the stronger thesis directly. But it is useful to consider questions Q1-Q3 on their own. By proceeding this way, we can distinguish more easily between challenges to the primacy of representation in perception that arise at different levels of generality, and we can examine the role of representation in experienced mandates more fully. In addition, my route to identifying contents that could in principle reflect mandates suggests a strategy for defending the stronger claim. Without offering a full defense of the claim, l'll outline the argumentative strategy at the end.

\section{Part I. Experienced mandates}

\section{Affordances and experienced mandates}

Experienced mandates are a kind of experience of a type of affordance. We can characterize them more fully, by locating them in relation to three kinds of affordances that are good candidates for being experienced.

Proto-affordances are possibilities unrelated to agency, either because they are possibilities for objects that lack agency, or they are possibilities to which a subject's agency is irrelevant. Suppose you see a ball with its edge resting on the stalk of a plant on a hill, another rock teetering on the edge of a cliff, and a path with two people walking toward each other. The proto-affordances here include the rollability of the ball down the hill, the possibility that the teetering rock could fall off the cliff, and the fact that the two hikers could pass one another without stopping or colliding. If a subject perceptually experienced them, these proto-affordances would characterize how the ball, the rock, the path, and the pedestrians look to that subject. One might associate various actions with the proto-affordances, such as freeing the ball, tipping over the rock, or moving aside to let an oncoming person pass. But in principle, a subject need 
not experience these actions as possible, simply in virtue of experiencing the protoaffordances that prompt the associations.

Unlike proto-affordances, affordances proper involve possibilities of action for a creature. Suppose you see a bed that you could plop down on to rest - it is not flimsy cardboard, or full of nails underneath, or a cavernous pit in disguise. If you experience this affordance, then you would experience the bed as a place to stop and rest. If the bed really was a cavernous pit in disguise, then your experience would be falsidical. Similarly, consider a tuft of hair that covers your interlocutor's left eye but could be moved aside, or a thick forest that would shelter you from heavy wind and rain. Here, the forest affords protection, and the tuft of hair affords being moved out of the way to provide better eye contact. If you experienced these affordances, you would experience the hair as covering the eye like a curtain that you could open to improve your eye contact, and the forest as a place that could shelter you. If the forest turned out to harbor monsters, or the interlocutor had only one eye, then these experiences would be falsidical.

The experiences of affordances l've described so far are fully characterized even if the subject does not feel invited, solicited, or prompted to enter the forest, move the hair, or plop down on the bed. We can say that an affordance by X (hair, forest, bed) of phi-ability is a non-soliciting affordance for a subject $S$, if $X$ is experienced by $S$ as affording phi-ability, but $\mathrm{X}$ is not experienced as soliciting, inviting, or otherwise prompting $S$ herself to phi. So if $X^{\prime}$ 's affordance is non-soliciting for $S$, it is experienced by $S$, and it is not experienced by $S$ as soliciting.

In contrast, suppose the in the midst of an important conversation the tuft of hair keeps falling over your interlocutor's eye, obstructing proper communication by interfering with eye contact. You might well experience the hair as an obstacle that should be moved away to allow for fuller eye contact. Or suppose you see a perfectly moist, frosted piece of chocolate cake resting on a plate with a fork on a napkin next to it. You might well feel solicited by the cake to eat it. Similarly, you might feel invited by the forest to enter it if you need shelter. We can say that an affordance by $\mathrm{X}$ (hair, forest, cake) of phi-ability is a soliciting affordance for a subject $S$, if it is experienced by $S$ as soliciting, inviting, or otherwise prompting $S$ herself to phi. ${ }^{6}$ So if $X^{\prime}$ s affordance solicits a subject $S$, then $X$ is experienced by $S$ as soliciting. ${ }^{7}$

\footnotetext{
${ }^{6}$ We can also be moved to action by unconscious perception of things. In a broader sense than the one used here, those perceptions would be perceptions of soliciting affordances as well.

7 I've called these affordances "soliciting affordances" and "non-soliciting affordances", and it is natural to call the corresponding experiences "soliciting experiences" and "nonsoliciting experiences." But please disregard any suggestion by these locutions that the affordances or the experiences are (or are felt as) the things that do the soliciting.
} 
One and the same thing could be experienced as affording different things on different occasions. A forest might be experienced as a shelter if you need protection, but as an obstacle to be circumvented if it stands between point $A$ where you are and point B where you're going. Similarly, the forest might be experienced as soliciting entrance on one occasion but not soliciting entrance on another, even if it is experienced as proto-affording shelter both times.

Among soliciting experiences, we could distinguish between increments of felt solicitation. A piece of cake might look perfectly positioned to be eaten, but not so appealing that you experience it as something that is calling out to be eaten. The hair over the eye might look easily movable, but you might have reconciled yourself to the hairstyle, so that you don't experience the hair as calling loudly to be moved aside. These are differences in increments of felt solicitation.

Experienced mandates belong to the category of soliciting experiences and have a high degree of felt solicitation. With the ball coming toward you in a tennis game, the felt solicitation to swing your racket and hit it might be so strong that no other option enters your mind.

But what exactly is it to feel solicited to do something (to phi) by a slice of cake, a forest, or a tennis ball? In particular, how does this feeling relate to a motivation or urge to phi? Conceptually, solicitation in the sense used here and motivation can come apart. Suppose you hear music that (you can tell) is designed to be danced to, but you feel completely unmoved by it to dance. ${ }^{8}$ The music, as you hear it, is telling you to dance, but you don't feel its pull. It is as if the music is trying to make you dance, but you are not cooperating and have no inclination to cooperate. Similarly, the neatly stacked colorful packs of candy thoughtfully placed at eye level in the grocery store check-out line are supposed to make us disposed to buy them. The exhortative tone of many advertisements on radio and television has an analog in visual displays, and we can feel that they are designed to propel us into purchasing the things advertised, even when we feel not at all moved to buy the allegedly indispensable item. It might seem natural to call any experience of exhortation an experienced mandate. If seeing a piece of cake moves you to want to eat it when you weren't even hungry to begin with, you are mobilized from scratch in just the way that advertisers dream of. But advertisers' coercive intentions of to generate desires often detectable, even when the coercion does not succeed. I reserve the label "experienced mandate" for soliciting experiences involving some increment of motivation to do what is solicited.

According to a soliciting experience, the bearer of the affordance solicits you to phi, and according to a non-soliciting experience, something affords phi-ing.

${ }^{8}$ I thank Farid Masrour for this example. 
The phenomenal aspect of experienced mandates whereby they are motivated constitutes what I'll call a feeling of answerability. This feeling also normally results from hearing one's name called or from meeting another person's gaze. (Given the developmental importance of joint attention, we should expect special sensitivity to the direction of other people's gaze.) We say that a person answers to one name but not to another (e.g., "Julia" but not "Julie"). To "feel answerable to 'Julia'" does not mean that one can answer to "Julia", it means that one does answer to Julia.

Like answerability itself, the feeling of answerability is structurally similar to responsibility: you can shirk a responsibility, but you won't thereby cease to be responsible. Similarly, so long you feel answerable to something, even ignoring it is a response. But the feeling of answerability falls far short of answerability itself. If you are answerable to someone else, let us suppose, you take them to be a source of normative constraint on you. In feeling answerable to the dance music's solicitation to dance, or to the cake's solicitation to eat it, you do not thereby experience the music or the cake as a source of normative constraint on you.

We can zero in further on the feeling of answerability by examining delusions of reference. ${ }^{9}$ Consider the difference between the experience of someone looking at you when you're in the same room, and the experience of someone on television looking at you by looking at the camera. In both cases, you feel looked at. But there is also a difference that is brought into focus by the deluded subjects who assimilate both cases to the live case. In such delusions, a subject watching TV feels that the anchorman is addressing her - not just whomever might be listening.

What do the deluded subjects feel, when they feel addressed by the anchorman on TV? They feel a need to negotiate social space that goes with being seen. The negotiation involves unavoidable response, either in answering or ignoring. Ignoring someone looking at you at least initially often feels different from being unaware of them of looking at you. The deluded subject feels moved by the anchorman in the way that others normally feel moved only by other people who are in the same immediate surroundings.

When the cake merely solicits you without leaving you feeling motivated to eat it, the cake looks as if it is to-be-eaten. The cake is like the anchorman, talking to you by talking to whomever is listening. In contrast, when the cake solicits you in a way that leaves you feeling compelled to eat it, the cake may again look as if it is to-be-eaten. But in addition, the cake is like a person looking at you. You feel answerable to it, the way the deluded subject feels answerable to the anchorman, or normals feel answerable to other people who meet their gaze.

\footnotetext{
${ }^{9}$ Bortolotti (2013)
} 
We can contrast experienced mandates with another superficially similar but ultimately distinct phenomenon. Suppose you are flying in an airplane and suddenly realize that you should have already cancelled the electricity service at your previous address, and must do it as soon as possible. It can seem natural to describe your conscious state at this moment as "experiencing a mandate to cancel your electricity service". You may feel poised and ready to make the requisite phone call, just as soon as the plane lands. But to the extent that your immediate surroundings are not ones in which you can or will cancel your electricity service - you don't have a phone, it wouldn't work anyway in flight, and for these reasons you don't intend to call until later on - this type of experience is not an experienced mandate in our sense. Whatever feeling of "mandate" you may have in this situation is not integrated into the situation you're currently in. It has no dynamic that unfolds in that situation, and does not absorb your perceptual attention. ${ }^{10}$ Whereas with the dance music you were solicited to do something but not motivated to do it, here you are motivated to something, without anything in your immediate environment soliciting you to do it. Experienced mandates involve affordances by the perceived environment that you're currently in. In experienced mandates, solicitation and motivation go together.

A final observation about experienced mandates is that the thing that one experiences as soliciting can either be localized in an object (cake, hair), or it can be an entire situation. Suppose you are alone on a narrow sidewalk, walking. The sidewalk affords following its path. Then someone turns a corner and begins walking toward you. They are still far off, and no one else is in between. In this completely ordinary situation, without having to think about it all, you assume that the person is going to continue walking toward you until you pass. And now the affordance of travel is more complicated. When your paths cross, the part of the sidewalk traversed by them will not be passable. But you don't yet know exactly which part this will be. The space has to be negotiated by adjusting your relative positions. Traversing the sidewalk's path is afforded, but it is not afforded simply by the sidewalk. It is afforded by the sidewalk together with the passerby, contingent on their cooperation. It remains to be seen what form the cooperation will take. The same possibilities are open to both of you: step aside to let the other pass, or continue on whatever path they open up for you? make clear gestures designed to acknowledge the other person, or play down the fact that

${ }^{10}$ An experience like the one described could unfold in the subject's immediate environment, if the subject was in an agitated state in which everything in the plane came to look like an obstacle to making the crucial phone call. Perhaps such a subject would experience their surroundings in the plane as anti-affording cancelling their electricity service. (In principle, though probably not in fact, a subject's agitation could even make oblong items start to look to them like phones). But to create an illuminating foil for experienced mandates, in the plane example I'm assuming that the subject is not even experiencing the environment as either affording or anti-affording the task of cancelling their electricity service. 
there's any interaction? acknowledge any adjustment they make, or just carry on? Besides these possible modes of full cooperation, there is also the possibility of grudging cooperation, borderline non-cooperation (barely move out of the way), or at an extreme, collision. $^{11}$

So experienced mandates are motivated, soliciting experiences of affordances of things in the immediate environment, including entire situations. These are the experiences that our questions Q1-Q3 are about.

We can distinguish between three temporal relationships an experience can bear to the mandated action that it presents. First, one might experience as mandatory an action not yet undertaken. Second, one might experience as mandatory an action now being completed as mandated. Third, one might retrospectively experience as having been mandated an action just completed.

These relations form a dynamic phenomenon, which can be described as sequence of experiences. I'll describe them in terms of an action A:

(i) an experience of: A being such that you must undertake it, because the immediate situation demands it.

(ii) an experience of: being about to undertake $A$, because the immediate situation demands it.

(iii) an experience of: now carrying out $A$, because the immediate situation demanded it.

In experience (i), you experience the mandate without executing the mandated action right then and there - before executing it, or without ever executing it. ${ }^{12}$ In principle, a situation could present the same affordance as mandated, first in way (i) and then subsequently in ways (ii) and (iii). But we shouldn't assimilate (i) to an anticipation of executing the action. Just as you might receive a mandate from someone else that you go on to ignore, so too you might experience a potential action (such as moving the hair aside) as mandatory in way (i), without going on to execute it, though possibly only at the cost of some dissonance.

\footnotetext{
${ }^{11}$ These possibilities are made vivid in T.G. Seuss's story The Zax, in which a north-going Zax and a south-going Zax are stopped in their tracks because neither will move out of the other's way.

12 Kelly (2006) suggests that experiences characterized in (i) are typical in perceiving shape and color constancies. In perceiving the color or shape of something, he argues, we are sensitive to an optimal point from which it could be viewed. He does not claim, however, that every experience of perceptual constancies is one in which we actually optimize our bodily position viz a viz the thing we're seeing.
} 
I'm going to use "experienced mandates" to denote dynamic experiences spanning types (i)-(iii). But in discussing how experienced mandates relate to representation, I'll focus mainly on experiences of type (i).

\section{How experienced mandates challenge the centrality of representation in perception}

Due to their combination of solicitation and motivation, experienced mandates are better candidates for showing representation in perceptual experience to be explanatorily dispensable, compared to experiences of non-soliciting affordances, or experiences of proto-affordances, or experiences that don't involve affordances at all.

In an experienced mandate, the current situation seems to determine the subsequent one. Since the subsequent situation seems already to be on the way when one has the current experience, one might think there is no need for the current experience to represent the possibility of acting in the way the situation mandates, and more generally, no need for experiential representations to guide the subject in planning and executing the mandated action. With both solicitation and motivation built in to experienced mandates, it might seem natural to assimilate these experiences to action that is fueled by dynamic interaction with the environment.

We find something like this challenge in Dreyfus's description of experienced mandates. He does not discuss such experiences under that description, but he uses the metaphor of solicitation to describe them. At the start of one of his many discussions of skillful action, Dreyfus connects the central behaviorist idea that representations are not needed to mediate between the environment and behavior to Merleau-Ponty's notion of the "intentional arc":

Existential phenomenologists hold that the two most basic forms of intelligent behavior, learning, and skillful action, can be described and explained without recourse to mind or brain representations.... The intentional arc names the tight connection between the agent and the world, viz. that, as the agent acquires skills, these skills are "stored", not as representations in the mind, but as more and more refined dispositions to respond to the solicitations of more and more refined perceptions of the current situation. Maximum grip names the body's tendency to respond to these solicitations in such a way as to bring the current situation closer to the agent's sense of an optimal gestalt. I will argue that neither of these abilities requires mental or brain representations. (p. 1)

(I've highlighted the part about solicitations). In further explicating the kind of solicitation involved in Merleau-Ponty's notion of the intentional arc, Dreyfus appeals to the idea that skilled action is guided by a feeling of "tension" that tracks the status of 
the situation relative to one's goal: ${ }^{13}$ Dreyfus suggests that when a feeling of tension is sensitive to one's goal, it might obviate any need for representations to guide one's responses to the environment.

"In our skilled activity we move to achieve a better and better grip on our situation. For this movement towards maximum grip to take place, one does not need a mental representation of one's goal. Rather, acting is experienced as a steady flow of skillful activity in response to one's sense of the situation. Part of that experience is a sense that when one's situation deviates from some optimal body-environment relationship, one's activity takes one closer to that optimum and thereby relieves the "tension" of the deviation. One does not need to know what that optimum is. One's body is simply solicited by the situation to get into equilibrium with it." (p. 12)

Dreyfus illustrates further by discussing tennis:

[C]onsider a tennis swing. If one is a beginner or is off one's form one might find oneself making an effort to keep one's eye on the ball, keep the racket perpendicular to the court, hit the ball squarely, etc. But if one is expert at the game, things are going well, and one is absorbed in the game, what one experiences is more like one's arm going up and its being drawn to the appropriate position, the racket forming the optimal angle with the court -- an angle one need not even be aware of -- all this so as to complete the gestalt made up of the court, one's running opponent, and the oncoming ball. One feels that one's comportment was caused by the perceived conditions in such a way as to reduce a sense of deviation from some satisfactory gestalt. But that final gestalt need not be represented in one's mind. Indeed, it is not something one could represent. One only senses when one is getting closer or further away from the optimum. ("Intelligence without Representation")

Now, much of what we do is in a broad sense skilled action - a fact easily observed by watching toddlers in the midst of learning how to open doors or put on their shoes. In contrast, Dreyfus focuses on specialized skilled action (tennis), rather than on sensory-motor habits that nearly everyone eventually develops (tying shoes, opening doors). But experienced mandates can be found in the domain of sensorymotor habits as well. In the passerby example, one can imagine feeling that stepping aside to let the other person pass is mandatory, in the sense that among the possible modes of passing another person on the path, moving aside to let the other person pass

${ }^{13}$ The notion of tension comes from Merleau-Ponty, who uses it in Phenomenology of Perception to describe the phenomenon of perceptual constancies. He writes "The distance from me to the object is not a size which increases or decreases, but a tension which fluctuates around a norm." Quoted in Kelly (2010). 
is the only one experienced as possible, and in that sense, mandatory. The type of mandate can vary with the situation. Perhaps the passerby is frail, or moves only with difficulty, and the felt mandate stems from moral sensitivity. ${ }^{14}$ Or perhaps one has cultivated a habit of always letting the other person pass, out of politeness, or because one enjoys determining how such micro-interactions with the public unfold. Here too, the mandatory aspect stems not from specialized motor skill, but from a broadly social sensitivity. In yet other cases the felt mandate might be broadly aesthetic, as it is in the example involving the tuft of your interlocutor's hair that falls just in front of their left eye, making it harder to read their expression, and producing in you a strong impulse to move the hair out of the way. Or in an exhausted state, a fluffy bed in an empty room might be experienced as inviting you to plop down on it for rest. The felt mandate does not come from specialized skilled action or its dynamics of execution in any of these examples.

The challenge posed by experienced mandates to the primacy of representation is potentially quite powerful. Experienced mandates pervade much of our conscious lives, arising both in habitual action and in specialized skilled action. In light of the broad challenge, let us ask: what is the relationship between experienced mandates and representation?

\section{Part II. Experienced mandates and representation}

\section{Do experienced mandates have contents?}

We can begin our inquiry into this relationship by asking whether experienced mandates are experiences with accuracy conditions, where the accuracy conditions characterize how the environment seems to the subject to be. If an experience has accuracy conditions, then it is accurate only if those conditions are satisfied. When questions Q1-Q3 ask about the role of representational contents in experienced mandates, they are asking about the kind of accuracy condition that would characterize the experience from the subject's point of view. Discerning just which accuracy conditions do that is no small task. ${ }^{15}$ But some candidates naturally suggest themselves. For instance, if an experience of a tennis ball hurtling toward you has an accuracy condition, it might include the condition that the ball is green and coming toward you. A preliminary question, however, is whether experiences have any representational contents at all. And a version of that question concerns experienced mandates:

Q1. Do experienced mandates have any representational contents?

\footnotetext{
${ }^{14}$ In an excellent discussion of similar phenomena, Bengson (in progress), following Mandelbaum (1969) discusses an example of this sort, where someone gives up their seat on the bus to someone else who is visibly tired.

${ }^{15}$ We can't read off directly from introspection which contents experiences have. For discussion, see Siegel 2010, chapter 4.
} 
So far, I have glossed over the exact relationship that experienced mandates bear to perceptual experience, leaving open that they might simply be perceptual experiences, or alternatively they might have perceptual experiences as components. It seems obvious that perceptual experiences are related to experienced mandates in one of these two ways. You couldn't very well play tennis without seeing the ball, or seek protection by entering a forest without perceiving where the forest is in relation to you.

The central observation favoring the idea that perceptual experiences in experienced mandates are contentless is that the subject feels immediately solicited by their environment in ways that move them to action. There might then seem to be no explanatory role for contents of experience to play.

In reply, the fact that while acting easily in an environment, one is seemingly propelled by it does not undermine the general considerations about perception that suggest that such experiences have contents. Consider the case of visual experiences, since all of our examples involve vision. According to the Content View, all visual perceptual experiences have contents. The central motivation for the Content View is phenomenological. When you see things, they look to you to be a certain way. And when they look to you to be a certain way, they look to have certain properties. I won't repeat a full defense (given elsewhere) of the Content View here, but the key transition in that defense moves from ' $X$ looks to have property $F$ ' to 'The experience of $X$ 's having $F$ is accurate only if $X$ has $F^{\prime}{ }^{16}$

On the starting point of the transition, the fact that Dreyfus's tennis player can so easily navigate the tennis court does not entail that the things the player sees on the court - the player, the oncoming ball, the spaces between himself and net - fail to look any way to her at all. Without seeing the tennis court, it would be hard to play tennis and hard to perceive the gestalt to be completed. As Dreyfus observes, in the experience of playing tennis, there are some "perceived conditions" in response to which one adjusts one's movement. Since the adjustments are made to "complete the gestalt" of the tennis game, these perceived conditions presumably include the components of the gestalt, such as the positions of the opponent and the ball. Which ways these things look will depend on many factors, including what you're doing - such as whether you're playing the game, watching the players, or studying the court in order to draw it. But if the court, or the things in it, or the situation on the court didn't look any way to you at all, then you would not be seeing them. (Even if you are hallucinating rather than seeing, the same basic phenomenological point holds.)

In all of these cases, properties characterize the way things look to us, when we see them. And if things look to have certain properties, then, it seems, the experience is

\footnotetext{
${ }^{16}$ Siegel 2010 Chapter 2.
} 
accurate, only if things have the properties that they look to have. Of course positive reason is needed to think that in general, when things you see look to you to have certain properties, the experience are accurate only if the things are the way they look. A full defense of this transition is the core of my case for the Content View. What's important here is that nothing specific to experienced mandates forces any departure from the starting point of this general argument.

Although it may seem obvious from our examples so far that experienced mandates involve perceptual experiences, different examples might call this assumption into question. And if there are experienced mandates that extinguish all perceptual experiences as they unfold, then a fortiori no contentful perceptual experiences would play any important role analyzing experienced mandates. That result would open the possibility of denying that experienced mandates have representational contents, challenging the significance of the Content View while tolerating its truth.

One might hypothesize that the extinction of perceptual experiences is a special case of an ordinary occurrence, in which we exercise skills or habits without much guidance, if any, from perceptual experience. So it is worth considering whether some experienced mandates plausibly extinguish perceptual experiences we may start out having in earlier stages of habit or skill-formation, but which fade out completely by the time the habit or skill is well-established. Perhaps in some such cases, we form beliefs about what's around us, without basing those beliefs on any experience. One often doesn't need to look carefully, or at all, to see where to reach for a familiar doorknob, because one's body 'knows' already, out of sensory-motor habit, or thanks to unconscious visual processing in the dorsal stream. ${ }^{17}$

Could we be solicited by the environment without perceptual experience? Let us grant for the sake of argument that we could. Perhaps actions such as stuffing a tennis racket back into its case are sometimes completed without much need for perceptual experience at all. The same might be true of belief: one might believe that the racket is back in the case, without any conscious experience or memory of putting it there or seeing it slip in. It is uncontroversial that such actions proceed without deliberation. Might they proceed without experience as well? If experienced mandates can extinguish perceptual experiences, then even if all such experiences have content (as per the Content View), the Content View would not illuminate the role of perception in action or belief in cases of experienced mandates.

But there is little reason to think that experienced mandates extinguish perceptual experiences. It is one thing for motor habits to carry you through the actions of putting away the racket, or stepping aside so that the oncoming person can pass you on the narrow sidewalk, so that these aspects of your perceptual experience become

${ }^{17}$ Milner and Goodale (1995) 
highly inattentive and inaccessible to memory. It is something else for sensory-motor habits to blip out all surrounding perceptual experience, or for stepping aside to prevent you from consciously seeing the oncoming passer-by and the rest of the scene at all. If such occurrences were normal, our conscious lives would be interrupted with waking but blank durations, like seizures sprinkled throughout the day, triggered by habitual actions like putting away a tennis racket, filling up one's tea kettle, or opening the mailbox. The habit-discontinuity thesis (HD) is that such discontinuities occur on a regular basis with habitual actions.

The HD thesis predicts that we could never take in novel stimuli at the level of experience or notice anything unusual while completing habitual actions - actions that presumably don't use up much attention. Since habitual actions would seem to free up attention rather than expending it, this prediction is likely to be false, if the usual moral drawn from inattentional blindness experiments are correct. The usual moral is that draining our overall attentional resources with a demanding visual task that reduces our capacity for experience, or our capacity to remember it.

The HD thesis also predicts that most of the time when we reflect afterward on whether anything was visible to us while we were completing such actions, we would find that our memories were blank. It seems plain that this prediction is wrong. It's a familiar occurrence that we complete a habitual action, realize afterward we were paying little attention to what we were doing, and yet can still remember how other parts of the scene looked as we were completing it. You might not realize that you were sliding the tennis racket back into its case, or adjusting your position on a path to let other pass more easily, yet plainly these inattentive actions are sometimes accompanied by your noticing the sunset or hearing that the passer-bys were speaking German.

So far, I've argued that experienced mandates provide no special reason to back away from the standard reasons to think that perceptual experiences have contents. Against the assumption that perceptual experiences have contents, do any of these contents pertain especially to the felt mandate? This question is sharpened in the form of Q2.

Q2. Do experienced mandates have any representational contents relevant to explaining why it makes sense to the subject to perform the action she experiences as mandated?

Let's say that a content of an experienced mandate is explanatorily relevant, if it is relevant to explaining why it makes sense to the subject to perform the action that she experiences as mandated. For instance, in the hair case, if the subject moves the hair out of the way, then the content "hair is front of eyes" and "hair is to-be-moved" would be explanatorily relevant. This notion of explanatory relevance is considerably loose, but we won't need more precision in order to address Q2. 
We can distinguish between two kinds of properties that the component perceptual experiences might represent, and then consider whether contents involving each kind of property are explanatorily relevant.

First, the content could involve properties that rationalize the mandated action. This notion is best introduced through examples. When the interlocutor's hair looks to be covering one eye, it mandates adjustment. When the bed looks fluffy, it mandates plopping down on it. When the forest looks canopied, it mandates entering the forest. The ways the hair, the bed and the forest look in these examples (covering one eye, fluffy, canopied) are rationalizing properties, in the sense that the fact that those things have those properties makes the action involved in the mandate straightforwardly intelligible. Adjusting the hair is intelligible if the hair covers an eye, plopping down on the bed is intelligible if it is fluffy, seeking protection in the forest is intelligible if the forest is canopied. If rationalizing properties figured in the accuracy conditions of these examples, then experiences would be accurate only if: the hair covers the eye, the bed is fluffy, the forest is canopied.

Second, the content could involve properties that don't rationalize the mandated action. For instance, the ball is green, the hair is blonde, the forest trees are swaying in the wind. In these examples, the properties green, blonde, and swaying are nonrationalizing. In an experimental setting, one might operationalize the notion of nonrationalizing properties as task-irrelevant information. Let us begin with these nonrationalizing properties and ask whether contents involving them are explanatorily relevant, in the sense that Q2 asks about.

Consider Dreyfus's example of a chessmaster playing lightning chess, in which there is barely time to look at the board before the next move rearranges the pieces on it. How does the chessboard look to such a player? Dreyfus suggests that at the very least the master sees patterns of pieces on the board, even if their expertise leaves them with no need to reason explicitly from those patterns to the next move:

After responding to an estimated million specific chess positions in the process of becoming a chess master, the master confronted with a new position, spontaneously does something similar to what has previously worked, and lo and behold, it usually works. In general, instead of relying on rules and standards to decide on or to justify her actions, the expert immediately responds to the current concrete situation....When the Grandmaster is playing lightning chess, as far as he can tell, he is simply responding to the patterns on the board. At this speed he must depend entirely on perception and not at all on analysis and comparison of alternatives. ${ }^{18}$

${ }^{18}$ Dreyfus 2005, p.8 of web version. 
The chessboard looks to have its pieces positioned in a certain way. Perhaps only the relevant pieces appear any way to the chessmaster, and the pieces she knows to be irrelevant to that stage of the game are attentionally suppressed. ${ }^{19}$ Different parts of the board are presumably salient to the chessmaster than would be salient to the novice in those extremely brief periods between chess moves. The chessmaster's expertise might reduce the level of attentiveness to the overall state of the board, without going so far as to extinguish the experience of the board altogether. If so, the experienced mandate would structure the perceiver's attention, but wouldn't be systematically related to the contents of component perceptual experience, in the way that rationalizing properties rationalizing mandated action.

By hypothesis, subjects of experienced mandates experience themselves as being pushed forward from one moment to the next by the situation they're in. One might think this makes non-rationalizing contents of experience dispensable in guiding action. But that thought seems mistaken. Even if the mandates afforded to the chessmasters, for example, have no systematic impact on the contents of their experience, it is implausible to suppose that a chessmaster could play lightning chess without experiencing the board at all. By Dreyfus's own description, the chessmaster "depends entirely on perception" in playing the game. Their experiences of the board seem indispensable in guiding their action, or in explaining why the action makes sense to them, even if they are not rationalized in any way that we or they could reconstruct from the nonrationalizing contents.

Turning to contents that involve rationalizing properties, it might seem obvious that these properties play an explanatorily role in making the action seem appropriate to the subject. But the role of such contents in an experienced mandate could differ, depending on the direction of explanatory priority. In the content-first direction, you experience the mandate (move the hair, hit the ball back, enter the forest, etc), because the component perceptual experience represents the rationalizing property. Here the forest mandates entering it, at least partly because it looks canopied. Alternatively, in the action-first direction, the component perceptual experience represents a rationalizing property, because you experience the mandate. In this case, the forest would look canopied, at least partly because the experience mandates entering it. A third option is neither factor is explanatorily prior to the other (perhaps they are connected by a feedback loop).

In the content-first and feedback loop options, the contents of the perceptual experience could clearly help explain why the subject performs the mandated action. First, they contribute to making the affordance salient, and this helps explain why it is experienced as a mandate. Second, since on these options the component perceptual experience is explanatorily upstream of the experienced mandate, they help explain the

${ }^{19}$ On attentional suppression see van Rullen and Koch (2003). 
role of the experienced mandate in guiding action.

What if the rationalizing contents are related to the mandate in the action-first direction (e.g., the bed looks fluffy, because the subject experiences plopping down on it as mandated)? The perceiver collapses onto the bed because she is exhausted, not because of the way the bed looks to her. Here the contentful sub-experience contributes to the perceiver's intellectual coherence and integrity. Compare a case of psychological (as opposed to normative) rationalization. When people with excessive fear of heights stand on high balconies, their acrophobia ends up exaggerating how high they believe the balcony to be, compared to height estimates by non-acrophobes ${ }^{20}$ Let us suppose for the sake of argument that they don't fear the height because the balcony seems so high off the ground, but rather that the balcony seems so high off the ground in part because they are afraid of heights. On the assumption that with all else equal, it is more reasonable to be nervous about standing on a higher balcony than a lower one, the acrophobes' mistaken belief about how high the balcony is brings their fear into harmony with beliefs - even if the beliefs themselves are unreasonable, caused as they are by an excessive fear, rather than by an accurate assessment of the situation. Even the craziest, most irrational subjects sometimes display this type of internal cognitive harmony, such as the schizophrenic patient who is highly anxious because he thinks that the world is about to end and finds the arrangement of chess pieces on the chessboard to be ominous.

In these cases, the beliefs that the chess pieces are ominous and that the balcony is very high rationalize the background anxiety or fear in something like the way that the fluffy-bed experience and the contentful sub-experiences in our other examples rationalize experienced mandates. The contentful states in all of these cases, whether they are beliefs or experiences, give us a way to describe this phenomenon in which subjects (or their subpersonal processes) bring their psychological states into a type of cognitive harmony. ${ }^{21}$ To the extent that contentful states figure in these processes, they are not explanatorily idle.

Let us turn to the third question about the role of representation in experienced mandates.

${ }^{20}$ Stefanucci and Proffitt (2009) provide some evidence that something like this phenomenon actually occurs. Using a variety of measures, both acrophobes and nonacrophobes tend to overestimate the height of balconies they are standing on, but acrophobes exaggerate the height substantially more than non-acrophobes.

${ }^{21}$ If perceptual experiences stand in rational relations to one another, then they belong to a domain in which rational assessment apply. For discussion of larger implications for this idea for epistemology, see Siegel 2013 and Siegel (forthcoming). 
Q3. Is there any proposition that could reflect the mandate that the subject experiences, if that proposition were the content of the experience?

If all we knew about a subject's perceptual experience is that it had nonrationalizing properties, then we could not read off from her perceptual experience the fact that a subject feels solicited to do something by her environment, let alone that she is motivated to meet the situation with the solicited action. Neither could we read this off from the fact that the experience represents properties that would rationalize plopping down on a bed or moving a tuft of hair out of the way. Some other aspect of the experience would have to account for the soliciting and the motivating aspects of experienced mandates.

Can we identify a proposition that could reflect both the soliciting and motivating aspects of experienced mandates? Let us start with the soliciting aspect of experienced mandates. How could contents locate the solicitation in something perceptually experienced? Contents of the form " $X$ is to-be-phi' $d$ ", such as 'the hair is to-be-moved', 'the passerby is to-be-made-way-for' are a straightforward way to characterize the mandated action, while preserving the idea that the mandate is experienced as issued by something external that we perceive. Consider the difference between the predicates "to-be-phi'd" and "to-be-done". Whereas "to-be-moved-out-ofthe-way" is applied to the interlocutor's tuft of hair or to some other obstacle, "to-bedone" is applied to actions, such as moving hair out of the way, or making room on the sidewalk. Given the assumption that solicitations are experienced as being issued by things like cake and forests, a natural hypothesis is that experienced mandates represent specific to-be-phi'd properties, attributing them to things perceptually experienced.

What about the motivating aspect of experienced mandates? To bring this aspect of experienced mandates back into focus, recall the two music cases. The two experiences of music both solicit dancing, but they differ in whether they motivate the perceiver to dance. What, if anything, can differentiate between pairs of cases that differ only in this way, consistently with experiencing the mandate as issuing from the thing perceived? Could the motivational part of the mandate be reflected in contents that characterize how the music sounds, or how the forest, hair, sidewalk, tennis ball etc look?

One might think this aspect of experienced mandates is not representable in experience, on the grounds that it is a conative state, and experiences only take a stand on how the world actually is, not on how one wants it to be or is motivated to shape it. If Hume, Searle, and others who endorse this sharp division are right, then at most, the soliciting aspect of experienced mandates could be represented in experience.

A first attempt to find a place for the motivating aspect of experienced mandates in accuracy conditions adds the issuing of a mandate by $X$ (cake, forest, hair, etc) to the 
'to-be-phi'd property. The result would be that experience has conjunction of contents. Here are some candidates for the conjunction:

Exp: $X$ is to-be-phi' $d$ and $X . .$.

...wants me to phi

...is telling me to phi

...commands me to phi

...intends for me to phi.

But this option does not identify any difference between the two music cases, for the same reason that ' $X$ is to-be-phi' $d$ ' does not identify any such difference. One need not feel moved by what $X$ wants, tells you, or intends. As evidenced by long-standing, unfulfilled to-do lists, representing that something is to be done, for instance by writing it down on a list of things to do, does not suffice to motivate you to do it.

A different strategy is to complicate the second component of content further, by adding a causal relation that links the soliciting aspects to a desire or an action:

- Exp: $X$ is to-be-phi'd, and the fact that $X$ is to-be-phi'd

...makes me want to phi.

...is making me phi.

- Exp: $X$ is to-be-phi'd, and because $X$ is to-be-phi'd, I am going to phi.

These proposals posit ascriptions of one's own desires or intensions as part of the content of experience, and one might worry that this fails to respect the way in which perceptual experience is directed outward, characterizing things external to the subejct's mind. The phenomenal integration of solicitation and motivation is reflected in the unreflective nature of habitual and specialized skilled action. Sartre describes the integration when he uses a locution of the form "to-be-phi'd" to describe being "plunged into the world of objects":

When I run after a streetcar, when I look at the time, when I am absorbed in contemplating a portrait, there is no I. There is consciousness of the streetcar-havingto-be-overtaken... I am then plunged into the world of objects; it is they which constitute the unity of my consciousness; it is they which present themselves with values, with attractive and repellant qualities - but I have disappeared; I have annihilated myself. There is no place for me on this level. And this is not a matter of 
chance, due to a momentary lapse of attention, but happens because of the very structure of consciousness. ${ }^{22}$

Sartre may overstate the 'disappearance of the subject'. Representations of directionality and distance have an implicit first-person component, so contents involving the subject seem indispensable. But he seems right that the subject disappears as a subject of desire. We need not be aware of our motivation to hit the tennis ball, or flick the light switch, or move aside to let the oncoming pedestrian pass. We're just aware of the ball, the switch, the sidewalk, etc.

A more promising proposal is that the motivating aspect of experienced mandate casts its shadow on the contents of experience, in the form of contents that include a property related to answerability. What's needed is a hypothesis that identifies contents that are correlated with the feeling of answerability to a soliciting affordance. ${ }^{23}$ The effort to find such contents may seem futile, for any of three reasons:

- Challenge 1: The feeling of answerability has no internal structure to it, because it is a simple 'buzz' akin to a valence that attaches to thing you feel answerable to.

- Challenge 2: The feeling of answerability belongs on the side of the force-content distinction belonging to force.

- Challenge 3: The only contents that are correlated with the feeling of answerability in experienced mandates are a version of " $A$ is to-be-done", and these have the same problem considered earlier. From the fact that you represent something as to-be-done, it does not follow that you are motivated to do A.

Regarding the first challenge, assuming the notion of a felt valence has psychological validity, it seems reasonable to suppose that it figures in feelings of answerability in experienced mandates. ${ }^{24}$ But it is doubtful that the felt valences exhaust those feelings of answerability. If a pack of chewing gum looks appealing, it need not cost you any dissonance to ignore it. Here the perception of the gum does not involve any persisting inner mobilization of the sort that characterizes the feeling of answerability.

The other two challenges are not easily rejected. On the face of it, feeling answerable to a solicitation seems to be a mode of experiencing the solicitation. One experiences it in a mobilizing way, as opposed to experiencing it indifferently. This observation suggests that it must belong on the side of the force/content distinction belonging to force. And while a natural candidate for an accuracy condition associated with the feeling of answerability would seem to be "A is to-be-answered", this

\footnotetext{
22 Jean-Paul Sartre, The Transcendence of the Ego 1957, pp.48-49. I put in bold the locution of interest.

${ }^{23}$ I leave open whether the contents are constitutively linked to the phenomenal character, rather than being merely correlated with them.

${ }^{24}$ For discussion of microvalences, see Lebrecht et al (2012).
} 
suggestion invites the charge that like other 'to-be-phi'd' contents, it too can be entertained indifferently.

The strongest answer to these substantial challenges combines structural considerations with closer attention to what is experienced in the feelings of answerability that are at issue. The structural consideration is that contents could have a nested structure that reflects the main idea driving Challenge 2 . The nested structure seems to respect the fact that there are both motivated and indifferent ways to experience soliciting affordances. Leaving a crucial element partly blank for now, the structure could be this:

Experience: [It is <.....answerability...> that: $X$ is to-be-phi'd].

What fills in the ellipsis to create an accuracy condition? "...to-be-answered..." sounds prospective, and suggests that answering to the soliciting affordance is something the subject may or may not go on to do, whereas what we're looking for is a way to reflect the fact that the subject is already answering to the soliciting affordance. A better proposal is thus:

Experience: [It is answered that: $\mathrm{X}$ is to-be-phi'd.]

I'll call the contents on the right side of the word "Experience" answerability contents.

Of course these contents are not anything one would find natural to say in describing the experience. But the same is true of many other accuracy conditions such as special contents. The proposal here respects the integration of soliciting and motivating aspects of experienced mandates, and the fact that the soliciting affordance generates a feeling of answerability.

In cases where an experience also represents rationalizing properties, the contents embedded in "it is answered that" may be more complex, integrating the rationalizing properties with the to-be-phi'd property. For instance, "It is to be answered that: the bed is to-be-plopped down upon and is fluffy". I leave it open whether the rationalizing relation itself might be represented in experience, as would be reflected in contents such as "...to bed is to-be-plopped down upon because it is fluffy". ${ }^{25}$

What are some cases in which these accuracy conditions are met, and what are some cases in which they are not met? It seems plausible that the feeling of answerability suffices for the subject of the feeling to be answering to something in a minimal way - a way that does not consist in taking the thing that they are answering to (such as a piece of cake) to be a source of normative constraint. If so, then answerability contents are always correct. Compatibly with this result, a subject could in principle make an introspective error about whether she is or isn't feeling answerable to something.

${ }^{25}$ For discussion of seeing reasons, see Church 2010. 
In addition to probing the conditions under which answerability contents are true, we can also ask about the conditions under which the ' $X$ is to-be-phi' $d$ ' contents they embed are accurate. What would it take for it to be the case that the hair really is to-be-moved, or that the forest really is to-be-entered, the oncoming pedestrian is tobe-made-way-for, or that the cake really is to-be-eaten? These questions have no general answer, because the contents do not specify what kind of 'ought' underlies the mandate. For instance, if the morally correct thing to do on the path is move aside by giving the passerby lots of room to pass, then relative to moral 'ought', the pedestrian is to-be-made-way-for. In the hair case, relative to the 'ought' of social mores, it is not the case that the hair is to-be-moved, but perhaps relative to the 'ought' of communicative efficacy or aesthetic rightness, it is the case that the hair is to-be-moved (assuming that the interlocutor really does have an eye underneath the hair).

Even though answerability contents do not specify a norm relative to which they are accurate, which mandates a person experiences can indicate which norms she is sensitive to. In talking to a person you might feel a mandate to stop listening, or deeply discount what they say, or (on the other side) to put a lot of stock in what they say. Such experiences might manifest and perpetuate background attitudes of deference or disrespect. They illustrate the potential use of the framework of answerability contents in analyzing the interpersonal interactions. Such modes of aversion and approach can be the social instrument by which social patterns are maintained, such as patterns of exclusion and inclusion, or trust and dismissiveness.

These considerations can illuminate the conditions under which to-be-phi'd contents would be accurate. Relative to the social norms that such experienced mandates manifest, the answerability contents would be accurate, where relative to epistemic or moral norms, they might be inaccurate. For instance, if one experiences one's interlocutors comments as to-be-discounted when such discounting would be epistemically inappropriate, then the 'to-be-discounted' contents could be accurate relative to a social norm that mandates discounting, but inaccurate relative to epistemic norms.

The 'to-be-phi'd' contents that answerability contents embed are thus not complete accuracy conditions, because they leave unspecified a parameter that needs to be fixed in order to generate an accuracy condition. The reason to think this parameter is left unspecified is that there don't seem to be phenomenal differences that track different norms relative to which to-be-phi'd contents could be assessed for accuracy.

I've replied positively to question Q3 by arguing that answerability contents could identify a proposition that reflects that mandate that the subject experiences. Answerability contents are always true, and that embedded contents can be accurate or inaccurate only once an additional parameter is fixed. In light of these facts, does this response to Q3 concede anything to overall challenge to the primacy of representation from experienced mandates? To the extent that the embedded contents are accurate 
only relative to a type of norm that the experiences do not themselves specify, experienced mandates fail to provide full accuracy conditions by themselves. ${ }^{26}$ But rather than being irrelevant to experienced mandates, the proposal that experiences have answerability contents would let us express important features of this phenomenon. It would let us see rational relationships between subexperiences, it provides a framework for understanding mechanisms of social interactions including power relationships exerted through discourse, and it gives us a way to analyze common phenomenal strand throughout different forms of normativity. The remaining question is then whether experienced mandates have answerability contents.

\section{Do experienced mandates have answerability contents?}

With answerability contents on the table, we can return to the stronger thesis that experienced mandates have contents like these. This thesis goes beyond answering our initial three questions Q1-Q3. Can we discover whether experienced mandates have such contents?

A possible strategy starts from the substantial assumption that affordances can be represented in experience (and therefore experiences have accuracy conditions), rather than trying to defend the stronger thesis from the ground up. Given this assumption, one might try to argue for two conditionals:

Affordances $\rightarrow$ Solicitations: If affordances are represented in experience, then solicitations are too.

Solicitations $\rightarrow$ Mandates: If solicitations are represented in experience, then mandates are too.

Favoring the Affordance $\rightarrow$ Solicitation conditional, one might reason roughly as follows. From the cases of advertising and dance music, the feeling of being solicited by the environment to do something is familiar. If we are entitled (by our starting assumption) to use the idea that affordances are represented in experience to analyze perceptual experience, it is natural to use it for the special class of salient affordances that we experience as soliciting. There seems to be no principled bar to extending the analysis of perceptual experience from representing of affordances to representing the special case of soliciting affordances.

${ }^{26}$ Klein (2007) observes that experiences with imperatival contents (such as "step gingerly on your left foot") would not threaten representationalism about experience. This observation is true but irrelevant to the discussion of experienced mandates, since replacing the declarative content "the hair is to-be-moved" with the imperatival content "move the hair" would not suffice to reflect the motivated aspect of experienced mandates. 
Favoring the Solicitation $\rightarrow$ Mandate conditional, one could try to use the method of phenomenal contrast to evaluate hypotheses about what best explains of the phenomenal contrast between the two music cases, or another pair of cases in which two subjects seem to have experiences with the same solicitation content, but differ in whether they feel motivated to fulfill the solicitation they experience. The method could either be used to evaluate the hypothesis that the motivational aspect is best analyzed in terms of accuracy conditions of the form:

It is answered that: $\mathrm{X}$ is to-be-phi'd.

(The same cases and method could also be used to evaluate other hypothesis that posit different accuracy conditions, or something other than accuracy conditions). Since the burden of the strategy is to show that this is the best explanation of the phenomenal contrast, alternative hypotheses need to be considered. We considered some alternatives earlier in the conjunctive proposals, and the proposals that mirror Searle's hypothesis about the satisfaction conditions of perceptual experience. The alternatives also include one suggested by Dreyfus's remarks about the dynamic of tension and relief that fuel the intentional arc. This dynamic might be invoked to analyze both the soliciting and the motivating aspects of experienced mandates. Relief arises from meeting the situation with the mandated action, and tension from not meeting it that way, or from not yet having done so. Given these correlations, the dynamic of tension and relief is well-suited to guide the action, which is part of threatens to make the contents of perceptual experience explanatorily irrelevant.

But by itself, the dynamic of tension and relief does not account for the experience of solicitation per se. Nothing in the ebb and flow of tension and relief reflects the experience of hair, passerby, or forest soliciting one to perfection an action that will relieve the tension one feels in that situation. You might feel worse if you don't move the hair, and better if you do, but those facts could obtain even if you don't feel pulled by the hair to move it aside. One need not be "plunged into the world of objects" for the facts about tension and relief to hold.

This observation forms the basis of a dilemma concerning the relationship between the situation and the feelings of tensions and relief that it gives rise to. Either the course of tension and relief is merely caused by the situation in one's immediate environment, or else those feelings are psychologically more complex responses to the situation that involves some type of understanding what the situation demands. If the relationship is merely causal, then that relationship by itself does not illuminate how the situation is experienced as soliciting the action to which tension and relief are sensitive. If instead the tension and relief are byproduct of understanding of what the situation calls for, then that understanding, whatever form it takes, has just as much claim to guiding the action as the dynamic of tension and relief has. Either way, the dynamic of tension and relief by itself is inadequate to account for experiences of being solicited by things in the environment. 
I have outlined an argumentative strategy for the thesis that mandates are reflected in the contents of experienced mandates, and criticized one alternative explanation. To follow the strategy through, much more would need to be said about which pairs of experiences contrast phenomenally in the right way, and the alternative explanations of that contrast. But the discussion of questions Q1-Q3 suggests the strategy as a starting point.

\section{Conclusion}

Dreyfus and other writers who have described experienced mandates call attention to an important fact about perception: sometimes our perceptual experiences are pervasively structured by our role as agents responding to social situations. In other situations, our dominant mode is not that of an agent, but a spectator - for instance when we are freed from immediate pressures of spatial negotiation, simply taking in our surroundings. These writers are right to emphasize that phenomenologically, perception feels quite different depending on whether it is dominantly structured by our roles as agents or not. And that raises a question: to what extent are our experiences structured by experienced mandates, to what extent aren't they? An upshot of the discussion here is that even if the extent is great, the role of the spectator never disappears completely, even when we're in the throes of action. 


\section{References}

Bengson, J. (ms) "Practical Perception"

Bortolotti, L. (2010). "Delusion", The Stanford Encyclopedia of Philosophy (Fall 2010 Edition), Edward N. Zalta (ed.), URL =

<http://plato.stanford.edu/archives/fall2010/entries/delusion/>.

Church, J. (2010) "Seeing Reasons" Philosophy and Phenomenological Research 80 (3):638-670.

Cussins, A. (2003/1990) "Content, Conceptual Content, and Nonconceptual Content". In Y. Gunther ed. Essays in Nonconceptual Content. Cambridge: MIT Press.

Dreyfus, H. (2005) "Overcoming the Myth of the Mental: How philosophers can profit from the phenomenology of everyday expertise", Proceedings and Addresses of the American Philosophical Association, 79(2), pp. 47-65.Reprinted as "Overcoming the Myth of the Mental," Topoi, Vol. 25, No. 1-2:43-49 (2006).

Dreyfus, H. (2002) “Intelligence without Representation - Merleau-Ponty's critique of mental representation," Phenomenology and the Cognitive Sciences, Vol 1, No. 4, Special Issue: Hubert Dreyfus and the Problem of Representation, Anne Jaap Jacobson, Ed., (Kluwer Academic Publishers).

Dreyfus, H. "A Phenomenology of Skill Acquisition as the basis for a Merleau-Pontian Non-representationalist Cognitive Science"

Dreyfus, H. (2002) “Intelligence without Representation: Merleau-Ponty's Critique of Mental Representation" Phenomenology and the Cognitive Sciences 1: 367-83.

Gibson, J. (1977) "The Theory of Affordances" Reprinted in Perceiving, Acting, and Knowing, Eds. Robert Shaw and John Bransford, 1986, New Jersey: Laurence Erlbaum, pp. 127-1XX

Hurley, S. (2006) Consciousness in Action. Cambridge: Harvard University Press.

Kelly, S. (2006) "Seeing things in Merleau-Ponty" in The Cambridge Companion to Merleau-Ponty. Eds. T. Carman and M. Hansen. Pp. 74-110.

Kelly, S. (2010) "The Normative Nature of Perceptual Experience" in B. Nanay, Ed. Perceiving the World. Oxford University Press.

Klein, C. (2007) “An Imperative Theory of Pain” Journal of Philosophy 104 (10): 517-32. 
Lebrecht, S., M. Tarr, M. Bar, L. Feldman Barrett (2012) “Microvalences: Perceiving Valences in Everyday Objects". Frontiers in Psychology April 2012, Volume 3, Article 107.

Lessard, D. A., Linkenauger, S. A., \& Proffitt, D. R. (2009). Look before you leap: Jumping ability affects distance perception. Perception, 38(12), 1863-1866.

Linkenauger, S., Witt, J. K., Stefanucci, J. K., Bakdash, J. Z., \& Proffitt, D. R. (2009). The effects of handedness and reachability on perceived distance. Journal of experimental psychology. Human perception and performance, 35(6), 1649-60.

Mandelbaum, M. (1969) The Phenomenology of Moral Experience. Baltimore: Johns Hopkins Press.

Merleau-Ponty, M. (1962) Phenomenology of Perception. Routeledge and Kegan Paul.

Milner and Goodale (1995) The Visual Brain in Action. Oxford University Press.

Nanay, B. (2011) “Do We See Apples as Edible"? Pacific Philosophical Quarterly 92 (3):305-322.

Nanay, B. (2010) “Attention and Perceptual Content” Analysis 70 (2): 263-70.

Noë, A. (2006) Action in Perception. Cambridge: MIT Press.

Orlandi, N. (2014) The Innocent Eye. Oxford University Press.

Pautz, A. (2010) "Why Explain Visual Experience in terms of Content?" In B. Nanay, ed., Perceiving the World. Oxford University Press. 254-310.

Sartre, J. P. (1957) The Transcendence of the Ego. The Noonday Press.

Seuss Geisel, T. (1961) "The Zax", in The Sneetches and Other Stories. New York: Random House.

Siegel, S. (2010) The Contents of Visual Experience. New York: Oxford University Press.

Siegel, S. (forthcoming) How is Wishful Seeing like Wishful Thinking? Philosophy and Phenomenological Research.

Stefanucci, J. K., \& Proffitt, D. R. (2009). The roles of altitude and fear in the perception of height. Journal of experimental psychology. Human perception and performance, $35(2), 424-38$. 
Witt and Proffitt (2008) Action-specific influences on distance perception: a role for motor simulation. Journal of experimental psychology. Human perception and performance, 34(6), 1479-92.

van Rullen, R. and Koch, C. "Competition and selection during visual processing of natural scenes and objects" Journal of Vision (2003) 3, 75-85. 